
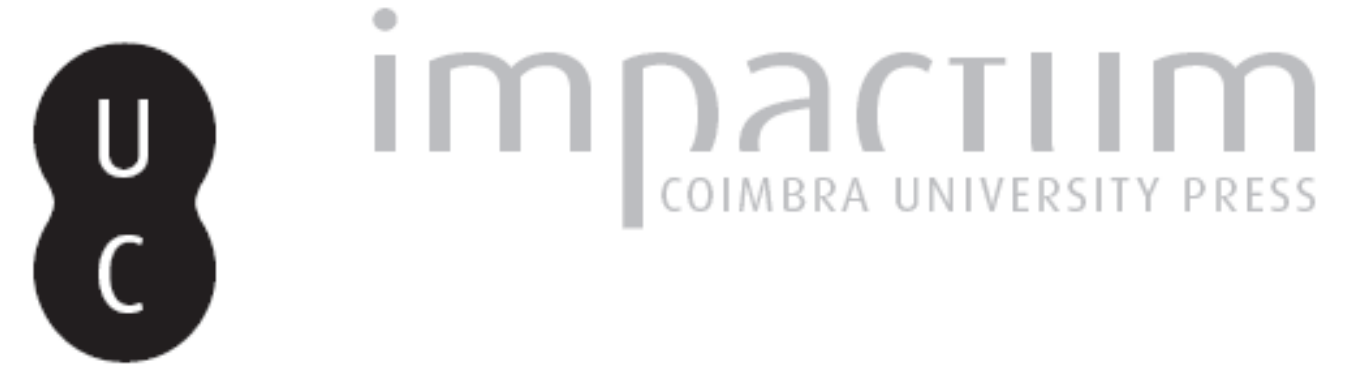

\title{
A produção textual na Universidade Brasileira e a construção do sentido: contradições acadêmicas e soluções possíveis
}

Autor(es): $\quad$ Oliveira, Elizabeth Antonia de

Publicado por: Imprensa da Universidade de Coimbra

URL persistente:

URI:http://hdl.handle.net/10316.2/42299

DOI:

DOI:https://doi.org/10.14195/2183-7260_61_12

Accessed : $\quad$ 26-Apr-2023 11:43:42

A navegação consulta e descarregamento dos títulos inseridos nas Bibliotecas Digitais UC Digitalis, UC Pombalina e UC Impactum, pressupõem a aceitação plena e sem reservas dos Termos e Condições de Uso destas Bibliotecas Digitais, disponíveis em https://digitalis.uc.pt/pt-pt/termos.

Conforme exposto nos referidos Termos e Condições de Uso, o descarregamento de títulos de acesso restrito requer uma licença válida de autorização devendo o utilizador aceder ao(s) documento(s) a partir de um endereço de IP da instituição detentora da supramencionada licença.

Ao utilizador é apenas permitido o descarregamento para uso pessoal, pelo que o emprego do(s) título(s) descarregado(s) para outro fim, designadamente comercial, carece de autorização do respetivo autor ou editor da obra.

Na medida em que todas as obras da UC Digitalis se encontram protegidas pelo Código do Direito de Autor e Direitos Conexos e demais legislação aplicável, toda a cópia, parcial ou total, deste documento, nos casos em que é legalmente admitida, deverá conter ou fazer-se acompanhar por este aviso.

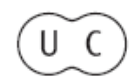




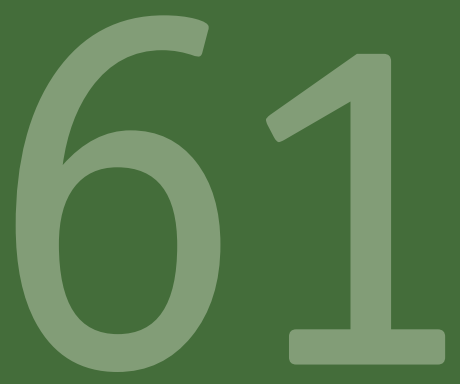

\title{
BOLETIM DE
}

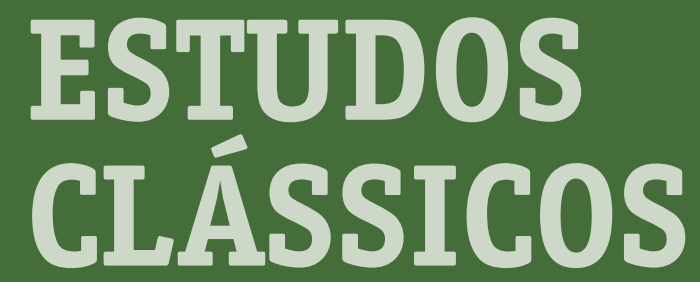

\author{
ASSOCIAÇÃO \\ PORTUGUESA \\ DE ESTUDOS \\ CLÁSSICOS \\ INSTITUTO \\ DE ESTUDOS \\ CLÁSSICOS
}




\title{
A PRODUÇÃO TEXTUAL NA UNIVERSIDADE BRASILEIRA E A CONSTRUÇÃO DO SENTIDO. CONTRADIÇÕES ACADÊMICAS E SOLUÇÕES POSSÍVEIS
}

\section{THE TEXTUAL PRODUCTION IN THE BRAZILIAN UNIVERSITY AND THE CONSTRUCTION OF THE MEANING. ACADEMIC CONTRADICTIONS AND POSSIBLE SOLUTIONS}

\author{
ELIZABETH ANTONIA DE OLIVEIRA ${ }^{1}$ \\ UNIVERSIDADE FEDERAL DE MINAS GERAIS \\ liz.antonia@hotmail.com
}

Resumo: A nossa vivência acadêmica vem confirmando um problema muito falado, mas pouco estudado: o fato de um número significativo de estudantes brasileiros chegarem à Universidade sem terem bom domínio, na lida com a escrita, do uso e dos movimentos que fazem com alguns recursos lógicos e retóricos. Clássicos da argumentação, principalmente Aristóteles, sustentam que o discurso se encaixa em

1 Integrou o grupo Oficinas de Leitura e Produção de Textos Acadêmicos de 2008 a 2011, em uma Universidade particular de Minas Gerais. Em 2009, em decorrência das atividades com o grupo Oficinas, passou a trabalhar como professora assistente na disciplina "Seminários: Leitura Produção de Textos Acadêmicos e Argumentação", no curso de Ciências Econômicas, da PUC-Minas, onde trabalhou até 2013. Doutora em Linguística pela UFMG, com estágio de um ano, de setembro de 2014 a setembro de 2015, na EHESS - Paris, através da CAPES - Coordenação de Aperfeiçoamento de Pessoal de Nível Superior. 
dois paradigmas: um primário e outro secundário. Logo, tendo em vista suas peculiaridades, o discurso acadêmico deveria estar colocado no segundo paradigma. Isso mostra que a construção do texto científico não é um processo simples. Como solução para o problema, propomos uma Pedagogia mais retórica, se assim podemos dizer, que, para trabalhar a escrita, priorize o treino.

Palavras-chave: produção textual; academia; contradições; treino.

Abstract: Our academic experience comes confirming a issue very much talked about, but not to much studied: the fact that an important quantity of Brazilian students arrives at the University without having a good command in deal with the writing, concerning the use and the movements that make with some logical and rhetorical resources. Classics of the argumentation, especially Aristotle, maintain that the speech fits into two paradigms: one primary and other one secondary. However, the academic speech should be placed into the second paradigm. This shows that the construction of scientific text isn't a simple process. As a solution to the problem, we propose a more rhetorical Pedagogy, if we can say like that, which, to works the writing, prioritizes the training.

Keywords: textual production; academy; contradictions; training.

\section{INTRODUÇÃO}

A nossa vivência acadêmica vem confirmando um problema muito falado, mas pouco estudado: o fato de um número significativo de estudantes brasileiros chegarem à Universidade sem terem ainda pleno domínio, na lida com a escrita, do uso e dos movimentos que fazem com alguns recursos tanto lógicos quanto retóricos da língua. Ou melhor: observamos que eles têm mais habilidades para manejar os instrumentos lógicos, mas não sabem muito bem o que fazer com eles, ou melhor, não 
sabem costurá-los, utilizando os recursos retóricos. Isso significa que, na hora de construir um texto acadêmico, não conseguem organizar claramente as ideias, o que torna difícil sustentar uma tese.

Nossa caminhada vem nos mostrando também que a construção do texto científico não é um processo simples, que surge em um passo de mágica. Muito pelo contrário. Tanto é, que os alunos que mais sobressaem passaram, geralmente, por um longo processo de treino $^{2}$ na leitura e também na escrita. Verificamos também que, normalmente, esses estudantes provêm de famílias que assinam jornais, revistas; que viajam, levam os filhos ao teatro etc. Isso significa que influências do meio, experiências pessoais, podem servir como um "termômetro", usado para determinar o que é ou não adequado para o padrão de escrita acadêmica.

A partir dessas nossas afirmações e questionamentos, tentaremos pontuar, neste artigo, algumas questões relativas ao domínio da escrita na Escola ${ }^{3}$, mas, sobretudo, relativas a possíveis contradições na sustentação de recursos lógicos e retóricos, por nós levantados em produções textuais acadêmicas ${ }^{4}$ (resenhas), trabalhadas durante a nossa caminhada docente. Antes, discutiremos um pouco sobre algumas especificidades da argumentação lógica e retórica.

\section{SISTEMATIZANDO NOSSO OBJETO DE PESQUISA}

Para pontuar os problemas levantados, fizemos um estudo qualitativo comparado de resenhas acadêmicas que foram produzidas

2 A palavra "treino" vem da retórica. É, na verdade, um termo polêmico, pois muitos professores relacionam o treino à "decoreba". No entanto, esses mesmos professores fazem, naturalmente, uso dele.

3 É nosso costume escrever Escola com E maiúsculo, o que, para nós, representa todas as instituições responsáveis pela construção do conhecimento, principalmente o cientifico.

4 As produções, resenhas acadêmicas, são o resultado de um trabalho que fizemos, como integrantes do grupo Oficinas de Leituras e Produção de Textos Acadêmicos, do curso de Letras de uma Universidade privada brasileira, entre os anos 2008 e 2011. 
nas Oficinas de Leitura e Produção de Textos Acadêmicos de uma Universidade privada de Minas Gerais, no ano de 2011. Para essa empreitada, primeiramente selecionamos cinco resenhas dos alunos do curso X, do Departamento de Ciências Econômicas e Gerenciais e cinco resenhas dos alunos do curso Y, do Departamento de Ciências Sociais. A média de resenhas produzidas por semestre, no primeiro curso, era de 10 a 12. As turmas eram formadas, geralmente, por, no máximo, 15 alunos. Já no segundo curso, a média era de apenas três resenhas por semestre e muitos alunos desistiam no meio do curso, que não era obrigatório. Desse total, separamos dois textos, cuja nota média foi 6 (a nota máxima era 10), os quais constituíram o corpus deste estudo.

Nas Oficinas ministradas no curso das Ciências Econômicas e Gerenciais, a sequência didática compreendeu a produção de esquemas, resumos e resenhas temáticas, sendo que as resenhas se tratavam da atividade final. Nesse Departamento, os temas a serem discutidos eram pré-definidos a cada semestre. Logo, os alunos deveriam elaborar as resenhas dentro do tema proposto. No curso das Ciências Sociais, foi trabalhada a mesma sequência didática, porém, a última atividade tratava-se de resenhas de divulgação ${ }^{5}$. Diferentemente das Ciências Econômicas e Gerenciais, nas Ciências Sociais os alunos produziam a partir de temas livres. É importante frisar que a resenha de divulgação é mais autoral do que a resenha temática, logo dá mais autonomia ao aluno. Não queremos dizer, com isso, que a resenha de divulgação seja um gênero menos importante, mas pode exigir menos do aluno, como já diagnosticamos.

Pontuamos também que, tendo em vista o prognóstico do início deste artigo, o que determinou a escolha desses dois cursos de áreas

5 O que nos fez comparar objetos um pouco distintos: resenhas temáticas e de divulgação, foi justamente o fato de não se vislumbrar a possibilidade de aplicar resenhas "mais complexas" (temáticas) nos alunos das Ciências Sociais. Isto é, já havia um pré-julgamento sobre a capacidade de produção textual desses sujeitos. 
distintas foi a possibilidade de uma comparação que explicitasse a importante variação por que passam as produções, de um curso para o outro. Isto é: nessa investigação, percebemos que, apesar de se tratarem de dois cursos superiores, que supostamente exigiriam mais ou menos o mesmo padrão de escrita, os alunos das Ciências Sociais vinham apresentando fundamental dificuldade com a produção textual, o que também marca a contradição que levantamos.

\section{MITOS E VERDADES SOBRE A PRODUÇÃO DE TEXTOS NA UNIVERSIDADE}

Acreditamos que o objetivo primeiro e último de todo texto é comunicar. Mas, existem outros, por exemplo: o ensino-aprendizagem. Logo, percebemos que, na Universidade, a produção textual pode chegar a ter, infelizmente, um caráter apenas avaliativo ${ }^{6}$. A comunicação e outras propostas passam, então, para um segundo plano. Porém, o que muitos teóricos têm sustentado é que, em qualquer situação de uso, o texto, no processo de construção do conhecimento, não pode ser somente um artefato abstrato. Ele nasce, conforme Aristóteles (2003), Saussure (1997), Bakhtin (1981 e 1992), e tantos outros estudiosos da língua e das linguagens, de um conjunto de vivências sociais, culturalmente construídas, em que os instrumentos lógicos e retóricos surgem naturalmente no cotidiano.

No entanto, na nossa vivência acadêmica, verificamos que algumas produções chegam a ter um caráter primário, mecânico, e, consequentemente, totalmente desprovido de sentido. Isto é, o sujeito social, muitas vezes, não consegue transpor o mundo dele para a academia. o texto se torna uma obrigação, sem gosto. Por esse e outros motivos, acreditamos que as produções acadêmicas podem, muitas vezes, ser vistas,

6 No Brasil, até o Ensino Médio, esse caráter unicamente avaliativo, em muitas situações, ainda é quase uma regra. 
principalmente por esses sujeitos, e também pelo professor, como um processo, cujo produto seria a nota, o que significa que o aluno pode estar produzindo apenas para cumprir uma formalidade acadêmica.

Possivelmente por fatores sócio-histórico-culturais, na lida primária e mecânica, alguns desses sujeitos não sentem ser o texto naturalmente interacional, como propõem alguns teóricos. A esse respeito, pensamos na noção de textos primários e secundários em Aristóteles (2003). Nessa perspectiva aristotélica, o homem "rude" é aquele que tem dificuldade de organizar textos mais bem elaborados; já a pessoa treinada é o sujeito apto a produzir bons textos, ou seja, textos "complexos". Mas, Aristóteles sustenta também que o produtor do texto não deve ser nem demasiado erudito nem demasiado rude. Logo, deve se adequar às diversas situações.

A partir desses dois paradigmas, surge uma questão: como, hoje, treinar estudantes universitários para se adequarem à situação acadêmica? Há uma receita para isso? Mendes (2010) defende que "o papel do ensino, mais do que nunca, deve ser o de ensinar a pensar e ensinar a aprender" (p. 11). Aqui, Mendes não está tratando de fórmulas prontas, mas de instrumentos metodológicos, que possam cooperar com o processo de aprendizagem do estudante. Logo, o processo deve ser longo, e não poderia, jamais, começar na Universidade.

Estamos usando, aqui, expressões como texto complexo, conhecimento complexo, para sustentar que a Escola, desde os níveis básicos até o superior, tem as suas especificidades: é o lugar da sistematização do conhecimento. Isto é, lida com padrões específicos de organização textual. Mendes (2010) observa que, de acordo com a Pedagogia Retórica ${ }^{7}$, na construção do conhecimento, as leituras devem ser feitas objetivando encontrar conteúdos e formas para as produções. Ela lembra ainda que a produção textual é uma atividade cognitiva

7 Discutiremos um pouco sobre a Pedagogia Retórica no item 4.2. 
diversa da leitura, e exige treinamento específico, que não pode se restringir à leitura ${ }^{8}$.

Sendo assim, como já propusemos, para um treino mais adequado, anterior à vida acadêmica, pensamos que se faz necessária a elaboração de bons projetos pedagógicos, através de políticas públicas, que sirvam para investimento urgente e sistemático na Escola básica brasileira. Esses projetos precisam, acima de tudo, pensar uma Pedagogia que não só invista no conhecimento complexo, mas que aponte caminhos para saberes extracientíficos; que mostrem, inclusive, outras possibilidades, além da Universidade.

De acordo com a Pedagogia Retórica, para dar conteúdo e forma a uma produção, podemos usar, por exemplo, a amplificação: atividade de composição situada entre a imitação e a criação ${ }^{9}$, a partir de um texto modelo. É aqui, entre a imitação e a criação, que acreditamos se encontrar o objeto de estudo, as resenhas temática e de divulgação, que analisaremos logo mais.

\section{DIALOGANDO COM ALGUMAS TEORIAS}

\section{a) Da lógica à retórica}

De acordo com os clássicos, a argumentação é marcada por três faces: a Lógica, a Dialética e a Retórica. A princípio, argumentação e retórica eram praticamente sinônimos, mas novas discussões redefiniram essas nomenclaturas. Como se sabe, a lógica baseia-se em argumentos demonstrativos, sustentados por fatos, dados, verdades, objetivando convencer o outro, logo, está ancorada na objetividade. O raciocínio mais adequado é o dedutivo ${ }^{10}$.

8 Mendes, 2010:199.

9 Sobre esses termos, ampliaremos a discussão também no item 4.2.

10 Discussão desenvolvida a partir do quadro proposto por Emediato, no livro "A Fórmula do Texto" (2010). 
A face dialética nasceu com os diálogos socráticos, escritos por Platão. Esses diálogos servem tanto para ensinar (a maiêutica) quanto para refutar (a ironia). Aqui, estamos tratando, claro, da dialética instrucional, e não da combativa. Logo, estamos pensando nos diálogos que o aluno pode estabelecer tanto com o professor quanto com os temas propostos, bem como com o mundo, objetivando a construção do conhecimento. Nessa perspectiva, o professor poderia ser a melhor audiência ou auditório do estudante. Mas, conforme já frisamos, muitas vezes o aluno vê o professor como um mero instrumento de combate, ou melhor, um avaliador, com quem o único feedback que pode dar é a nota. $O$ uso retórico serve-se de argumentos ideológicos, nele prevalecendo por vezes uma relação estreita entre os argumentos e o orador. A retórica confere lógica aos juízos de valor, visando garantir a persuasão, logo, a adesão do auditório. Assim, a retórica pode ter um caráter pragmático, e aparecer associada a uma etapa anterior da avaliação.

\section{b) Aprendendo com a Pedagogia Retórica}

Se a retórica tem um caráter pragmático, avaliativo, em plena relação o outro, por que tem sido, no Brasil, posicionada à margem da construção do conhecimento científico? Como ensinar o aluno a pensar e a aprender, como orienta Mendes (2010), à distância de uma Pedagogia Retórica? Mendes lembra que um dos objetivos da Pedagogia Retórica é, principalmente, preparar os aprendizes para falar e escrever bem.

A Pedagogia Retórica sustenta também que a leitura deve servir para encontrar conteúdos e formas para as produções, enquanto a escrita, como processo, serve para sistematizar o conhecimento. A partir dessas proposições, podemos buscar Cícero (1942), em De oratore, para quem três fatores relacionam-se à habilidade retórica, a saber: o talento, a teoria ou arte e a prática, que estamos chamando de treino. 
Esses fatores, em especial a prática, ou o treino, estão estreitamente relacionados a elementos contextualizadores, fundamentais, segundo a Pedagogia Retórica, para definir um bom texto. Entre eles, destacamos a imitação (imitatio), a paráfrase, a ampliação, a invenção (inuentio), a oralidade, a disposição (dispositio), os gêneros e tipos textuais, a oportunidade (kairós), a adequação do discurso (decorum). Resumindo, esses elementos servem para todas as esferas da construção do conhecimento científico.

Para as nossas análises, decidimos trabalhar principalmente com a imitatio, a inuentio e o decorum. A imitatio equivale a um modelo a seguir. Imitação, para Aristóteles, é o que faz o poeta, pois este é um imitador do real por excelência. Para Cícero (1942) a imitatio é uma estratégia pedagógica. Já a inuentio seria uma fase mais autônoma, que equivale a aprender a buscar ideias a partir de tópicos. É a participação consciente do sujeito no texto. $\mathrm{O}$ decorum apontaria se o aluno adequou bem o seu texto às exigências acadêmicas.

Voltando à imitatio, observamos que ela é tão importante, que tem uma estreita relação com as primeiras etapas da construção do conhecimento, mas é também amplamente utilizada na educação superior. Porém, é nesta etapa que principalmente a inuentio, a dispositio e o decorum estão estritamente ligados à organização do saber.

Sob essa rápida perspectiva teórica, partimos agora para as análises das duas produções textuais acadêmicas, resenhas, selecionadas para este estudo.

\section{MOMENTO DE REFLEXÃO - NOSSAS ANÁLISES}

Para chegar às nossas análises, apresentamos, inicialmente, as atividades propostas nos cursos das Ciências Econômicas e Gerenciais e das Ciências Sociais, com os quais foram trabalhadas, respectivamente, uma resenha temática e uma resenha de divulgação. 
Os elementos contextualizadores por nós destacados para esta etapa estão dispostos a seguir, em dois quadros distintos, com duas colunas cada, nas quais apontamos, à esquerda alguns aspectos lógicos e à direita, outros retóricos, todos levantados nas duas resenhas selecionadas para análise.

A) Resenha 1 - Ciências Econômicas e Gerenciais PROPOSTA

Caro aluno, agora que você já leu uma resenha crítica, bem como discutiu sobre as principais características linguístico-textuais e estruturais desse gênero, retome a resenha do livro "Como o futebol explica o mundo", de Franklin Foer, bem como o artigo de opinião "Cofres, copas e conchavos", do comentarista esportivo Sócrates, publicado na revista Carta Capital de 05.03.2011 e o artigo de opinião "Por que o Brasil", publicado no site http://www. copa2014.org.br/porque-o-brasil/, e produza uma resenha temática, para ser publicada no site deste Departamento ou no jornal do curso.

PRODUÇÃO - resenha temática

\section{Impactos da Copa de 2014}

Na perspectiva de Franklin Foer e do site "Porque o Brasil", o futebol é mais do que um esporte, ou mesmo um modo de vida. Os clubes de futebol espelham classes sociais e ideologias politicas, e frequentemente inspiram na devoção mais intensa que as religiões.

O gosto pelo futebol parece ser uma das poucas unanimidades nacionais do Brasil. 
Para realizar esse amplo e perspicaz trabalho de reportagem, Franklin viajou o mundo, analisando o intercâmbio entre o futebol e a nova economia global.

A Análise de Mobilidade da copa do mundo divide opiniões, Uns defendem que para o Brasil é a oportunidade de o pais dar um salto de modernização e apresentar não só sua capacidade de organização, como também força econômica para captar investimentos.

Os números de países que já sediaram a copa do mundo de futebol comprovam que o evento pode não ser o acontecimento esportivo de maior porte do planeta, mas com certeza é o que tem maior apelo mediático e capacidade de geração de recursos.

Realmente o custo-benefício deste evento é de complexa análise, mas de grande relevância na economia mundial.

\section{ANÁLISE}

\begin{tabular}{|c|c|}
\hline ASPECTOS LÓGICOS & ASPECTOS RETÓRICOS \\
\hline Fatos: futebol [...] modo de vida; & Imitatio: a sequência didática \\
\hline devoção; unanimidades; reporta- & trabalhada nas Oficinas orienta o \\
\hline gem; viajou o mundo; nova econo- & aluno a construir textos a partir \\
\hline mia global; opiniões; oportunida- & de metodologias e modelos pre- \\
\hline de; modernização; organização; & viamente discutidos. Mas, mes- \\
\hline força econômica; investimentos; & mo assim, o sujeito não se atém \\
\hline evento; acontecimeno esportivo. & à proposta. Problemas mais im- \\
\hline & portantes: estrutura (introdução, \\
\hline Dados: Franklin Foer; site & desenvolvimento e conclusão) e \\
\hline "Porque o Brasil"; futebol; esporte; & gerenciamento das vozes. \\
\hline clubes de futebol; classes socia & \\
\hline ideologias políticas; religiões; & Inuentio: o aluno organiza bem \\
\hline Brasil; o mundo; copa do mundo; & as ideias no texto, mas não dei- \\
\hline país; planeta; economia mundial. & xa claro quando ele está falando \\
\hline
\end{tabular}


Não fica claro se recorre a dois outros dados importantes, que são os outros dois textos indicados na proposta.

Raciocínio dedutivo: o futebol pode mudar a economia do país => mobilidade econômica; modernização; geração de recursos.

Objetividade: o aluno é objetivo, mesmo quando não consegue gerenciar bem as vozes e demonstrar quais os textos está discutindo. Isto é, pontua bem fatos e dados importantes.

Verdades: o resenhista traz como verdades fatos e dados que são conhecidos. Quem acompanhou o processo para a Copa de 2014, percebe que o autor reuniu, de acordo com os textos indicados, informações concretas sobre o assunto. Não soube, porém, gerenciar bem as vozes dos autores, ao resenhar, deixando sua "verdade" se misturar às outras "verdades". como sujeito acadêmico e quando dá voz a outrem. Porém, recorre, como já pontuamos à esquerda, a importantes instrumentos argumentativos. Destacamos aqui outros: "na perspectiva de"; "frequentemente"; "realmente"; "de grande relevância".

Decorum: o texto atende bem à proposta, no sentido de ser claro e coerente, porém, o resenhista peca no gerenciamento das vozes, importante exigência acadêmica.

Kairós: há relevante esforço da parte do aluno, visando à produção de uma resenha acadêmico temática.

Audiência: conforme já observamos, o produtor do texto não se atém à metodologia proposta para o gênero resenha temática. Parece não haver uma introdução, e falta definir melhor as etapas "introdução", "desenvolvimento" e "conclusão". Mas se esforça para ser dialógico. 
Na resenha temática produzida pelo aluno das Ciências Econômicas e Gerenciais, percebem-se, como já salientamos, algumas inadequações quanto ao gênero proposto. Na metodologia, não são bem claras as etapas "introdução", "desenvolvimento" e "conclusão". Além disso, há importante problema no gerenciamento das vozes, já que a voz do resenhista se mistura às vozes dos textos resenhados. Por fim, a conclusão não dá conta de sustentar a discussão abordada nos textos. Apesar dos problemas por nós destacados, o resenhista faz uma boa tentativa de se adequar à proposta. Podemos, então, dizer que o texto tem importantes traços do discurso secundário, mas falta melhor organização das ideias, isto é, de instrumentos retóricos.

B) Resenha 2 - Ciências Sociais

PROPOSTA

Neste caso, não houve uma proposta escrita, mas uma orientação expositiva sobre o gênero textual e sobre a produção textual que deveria ser trabalhada, no caso, resenha de divulgação. Como já observamos, o tema era livre.

PRODUÇÃo - resenha de divulgação

\section{Diversão garantida no Rio}

Para os fãs de diversão, samba e lindas paisagens, indico o filme "Rio" que estreiou há um mês e já bateu recorde de bilheteria.

As sessões lotadas por crianças e adultos são a prova do sucesso do longa. As pessoas que o assistiram mais de uma vez confirmaram que a diversão é garantida pela arara azul de estimação que não sabe voar, cuja dona, a jovem Ana que se apaixona pelo então pesquisador de arara azul, Carlos.

A caça à arara azul fica muito divertida quando o cenário é o palco do samba na cidade do Rio. Confiram! 
ANÁLISE

\begin{abstract}
ASPECTOS LóGICOS
Fatos: diversão; samba; o filme "Rio"; estreou; bateu recorde de bilheteria; sessões lotadas de crianças e adultos; sucesso; diversão; não sabe voar; apaixona; caça.
\end{abstract}

Dados: fãs; lindas paisagens; sessões; longa; pessoas; arara azul; dona da arara azul; pesquisador de arara azul; Carlos; cenário; palco do samba; cidade do Rio.

A resenha não traz dados importantes, como informações técnicas, local, datas, horários das sessões.

Raciocínio dedutivo: sessões lotadas por crianças e adultos são a prova de sucesso do filme.

Objetividade: o texto é objetivo porque traz fatos e dados importantes, que se integram de forma coesa e clara. No entanto, o resenhista

\section{ASPECTOS RETÓRICOS}

Imitatio: o aluno não consegue imitar a estrutura de uma resenha de divulgação, de acordo com a metodologia proposta para esse gênero, pois deixa de registrar importantes dados, por exemplo: ficha técnica, gênero do filme, local, datas e horários das sessões.

Inuentio: organiza bem as ideias, mas assume o posicionamento de um sujeito da mídia. Há muitos aspectos, argumentativos, dialógicos, mas pouco acadêmicos. Traz uma noção de espaço fotográfico bem definida na descrição do Rio de Janeiro, com destaque para elementos que caracterizam cultural e geograficamente o cenário.

Decorum: atende, em parte, à proposta de uma resenha de divulgação mediática, mas não se assemelha bem a um texto acadêmico. Poderia 
recorre a muitos instrumentos subjetivos: "lindas paisagens"; "sessões lotadas"; "diversão garantida"; "muito divertida"; "Confiram!".

Por se tratar de um texto de divulgação, o olhar tende a ser mesmo mais subjetivo.

Verdades: Aqui também, quem acompanha os eventos culturais no Brasil, pode confirmar os fatos e dados elencados pelo resenhista.

Intencionalmente ou não, ele não deixa claro qual é o enredo do filme. Não traz, também, informações técnicas. ser, segundo Aristóteles, um discurso primário.

Kairós: discussão despojada, livre, não científica. Há uma proximidade com a resenha de divulgação, mas faltam importantes informações técnicas.

Audiência: o resenhista, cuja produção é clara, mas tem um caráter primário, não dá conta do gênero textual proposto. Talvez, não serviria como atividade final. Vale reforçar que esse é um gênero que parece exigir menos treino do sujeito acadêmico, principalmente porque não demanda gerenciamento de vozes.

Na produção do aluno das Ciências Sociais percebe-se a opção pela informalidade textual. As marcas linguísticas deixam (entre) ver não um resenhista acadêmico, mas mediático, empolgado com a obra que divulga. Isso não é um erro; pelo contrário, é uma forma eficiente de garantir a adesão do auditório. Porém, ainda não atende à proposta de uma resenha de divulgação. Não há, na produção, conforme salientamos, informações técnicas importantes, o que confirma que esse texto pode ser chamado de discurso primário, ou seja, não acadêmico. 


\section{a) Fechando nossas análises}

A partir do nosso trabalho de análises, percebemos que a resenha temática, produzida pelo aluno das Ciências Econômicas e Gerenciais, apresenta significativa recorrência de instrumentos lógicos, não opinativos. Já a resenha de divulgação, trabalhada pelo aluno das Ciências Sociais, é marcada pela opinião do autor, tendo em vista a presença de instrumentos de subjetividade, salientando um caráter mais retórico do que lógico.

Mas, o que queremos destacar aqui é que há uma importante contradição nisso. No início deste artigo, pontuamos que o que ocorre nas produções é justamente o contrário. O estudante do curso que apresentou, durante o período que trabalhamos as oficinas (uma média de cinco anos), mais deficiência acadêmica, trouxe um texto rico em instrumentos retóricos, os quais estavam bem organizados. E, mais ainda, deixou de trazer importantes recursos lógicos. Uma possível resposta para isso é que, dentro da atividade proposta, o aluno das Ciências Sociais se sentiu mais livre dos padrões normativos da academia. Logo, houve fluidez na sua fala, que, então, tendeu a ser também menos acadêmica, o que já era uma característica do curso.

Segundo alguns clássicos da argumentação, principalmente Aristóteles e Cícero, a criação discursiva nasce dos lugares comuns, isto é, de tópicos que, a partir de nossa história, do meio em que vivemos, armazenamos na mente para orientações discursivas. Isso significa que, conforme já observamos, sujeitos que participam de grupos sociais mais restritos e comuns, como os familiares, podem ter mais habilidade com discursos primários, enquanto os sujeitos que participam de grupos mais amplos e complexos, como políticos, religiosos, acadêmicos etc., podem ampliar, mais facilmente, as habilidade para os discursos secundários.

\section{CONSIDERAÇÕES FINAIS}

Confirma-se, então, que o treino tem um caráter institucional e paradigmático. Logo, o estudante que não é devidamente treinado na 
"academia básica"11 e não participa de outras instituições complexas, pode chegar à Universidade despreparado para produzir textos secundários.

A solução aqui proposta, uma "Pedagogia mais retórica", poderia servir para a base da educação, sobretudo porque esse tipo de pedagogia se alimentaria de instrumentos que já estão inseridos no cotidiano da Escola Básica, mas na dependência de metodologias mais precisas. Por fim, acreditamos que não podemos imprimir ao Ensino Superior a responsabilidade de evitar o discurso primário, pois, como o próprio nome diz, uma Pedagogia Retórica atenderia justamente a base da educação.

\section{BIBLIOGRAFIA}

Aristóteles (2003), Arte Retórica e Arte Poética. Rio de Janeiro, Ediouro.

Bakhtin, M. (1992), A Estética da Criação Verbal. São Paulo, Martins Fontes.

Bakhtin, M. (Volochinov) (1981), Marxismo e Filosofia da Linguagem. São Paulo, Hucitec.

Cicero (1942), On the Orator: Books 1-2, Translated by E. W. Sutton, H. Rackham, Loeb Classical Library 348. Cambridge, MA, Harvard University Press.

Emediato, W. (2010). A Fórmula do Texto. São Paulo, Geração Editorial.

Mendes, E. A. M. (2010). A produção textual: Revitalizando a Pedagogia Retórica. Belo Horizonte, UFMG/FALE.

Saussure, F. (1997), Curso de Linguística Geral. São Paulo, Cultrix.

11 Trouxemos este termo: "academia básica", entre aspas, porque acreditamos que a solução para a Universidade no Brasil é um maior e melhor investimento na Escola básica. Inclusive porque o estudante bem preparado ali pode ter mais discernimento sobre o fato de ele ter ou não interesse pela vida acadêmica. 